\title{
Muscular hyperplasia ('cirrhosis') of the lung and bronchial dilatations as features of chronic diffuse fibrosing alveolitis
}

\author{
D. DAVIES, A. MACFARLANE, C. S. DARKE, AND \\ O. G. DO D G E
}

From Ransom Hospital, Mansfield, and the Royal Infirmary, Sheffield

Muscular 'cirrhosis' of the lung was first described by von Buhl in 1872 . An occasional case was described afterwards, but the number has increased in recent years. We have found 25 cases published between 1940 and 1964 that have conformed reasonably well to the accepted concept of the condition. Sixteen of these have come from the United States of America, four from Mexico, two from France, and one each from Scandinavia, Canada, and Britain. These cases are summarized in Table I, together with the five cases now reported. They have been published under various titles, the commonest being muscular cirrhosis of ? the lung, pulmonary muscular hyperplasia, and bronchiolar emphysema. Some cases published under these titles have not been included because

T A B LE I

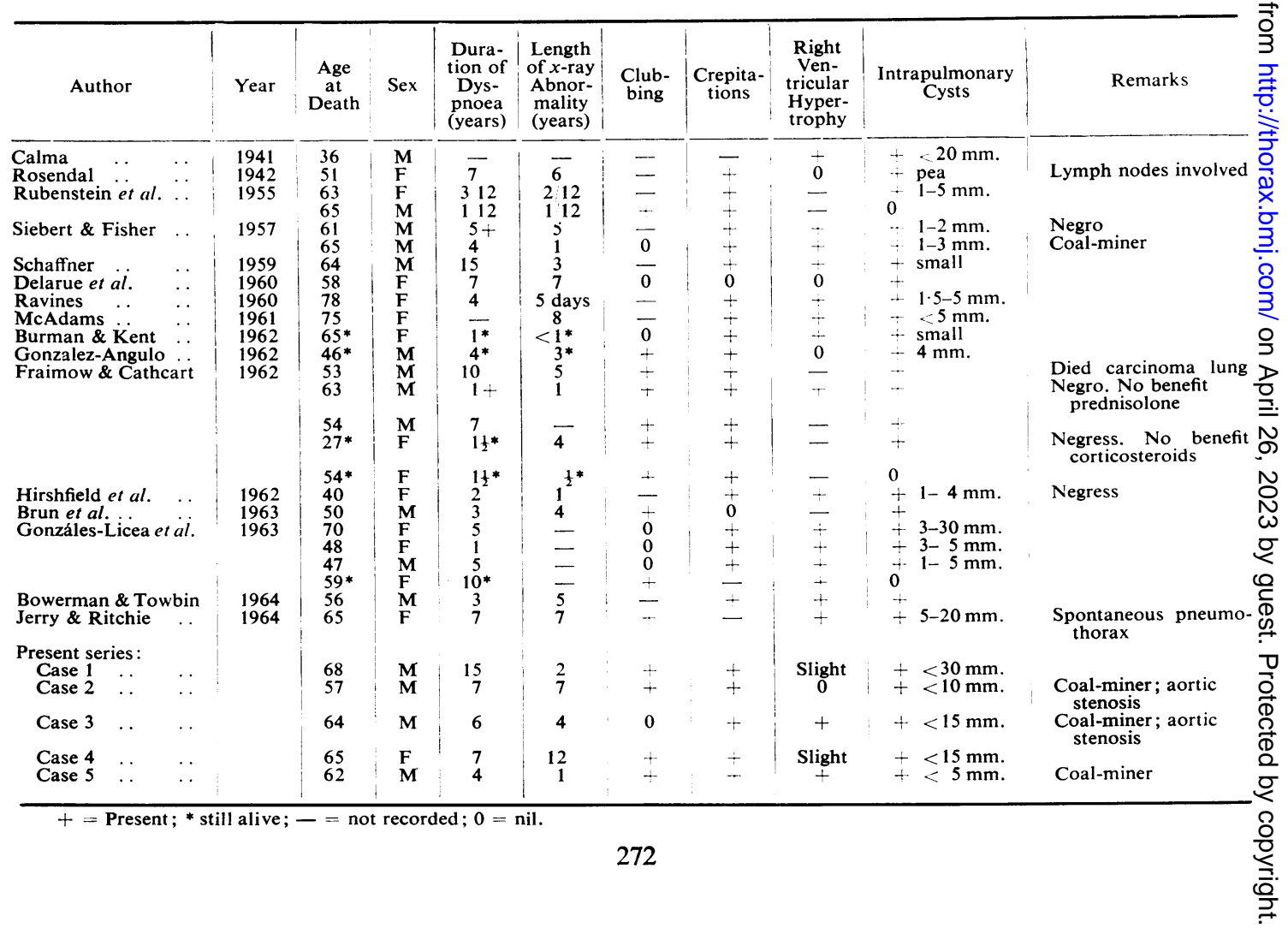


the information available is insufficient to make it reasonably certain that they fitted into the pattern.

Most of the patients have certain features in common. They were middle-aged or elderly men or women with a fairly long history of gradually increasing shortness of breath. With the exception of the cases of Rubenstein, Gutstein, and Lepow (1955), shortness of breath had been present for at least a year, four to seven years being the commonest range. In one of our patients dyspnoea was present for 15 years. Cough is a common symptom but is seldom distressing. Sputum may be present, but it is often absent or scanty. Wheezing is not a feature. Clubbing of the fingers and crepitations at the lung bases are frequent findings. Where respiratory function tests have been done there is a common pattern of reduced vital capacity without airways obstruction together with impairment of diffusion. Radiologically the lungs show diffuse bilateral mottling and fibrosis, occasionally with some shift of the mediastinum to one side. Honeycombing or small cysts may be visible. These features may show progression over a number of years. Spontaneous pneumothorax has only once been reported (Jerry and Ritchie, 1964). Five patients were still alive when reported, but death usually resulted from respiratory insufficiency or sometimes from right ventricular failure.

At necropsy the pleural spaces were usually free and the lungs small or fairly normal in volume. Their surface was often knobbly like a cirrhotic liver (Fig. 1). The cut surface usually, but not invariably, showed honeycombing affecting many parts, most of the cysts measuring 3 to $15 \mathrm{~mm}$. in diameter. Histologically the lungs showed little normal structure. In the honeycombed areas there was extensive loss of alveolar tissue and its replacement by fibrous tissue and muscle with little or no evidence of active inflammation. The surviving air spaces were dilated to form cysts which were often lined by cubical or columnar epithelium. There was a marked excess of smooth muscle, usually surrounding the air spaces and blood vessels but also lying scattered in haphazard fashion in the fibrous tissue and often in thick bundles under the pleura. The cases did not show clinical or necropsy evidence of such conditions as tuberose sclerosis, xanthomatosis, scleroderma, or rheumatoid arthritis. In one of our cases, however, the Rose-Waaler test was positive, as was the rheumatoid latex fixation test in another.

The clinical, radiological, and physiological pattern is indistinguishable from chronic diffuse

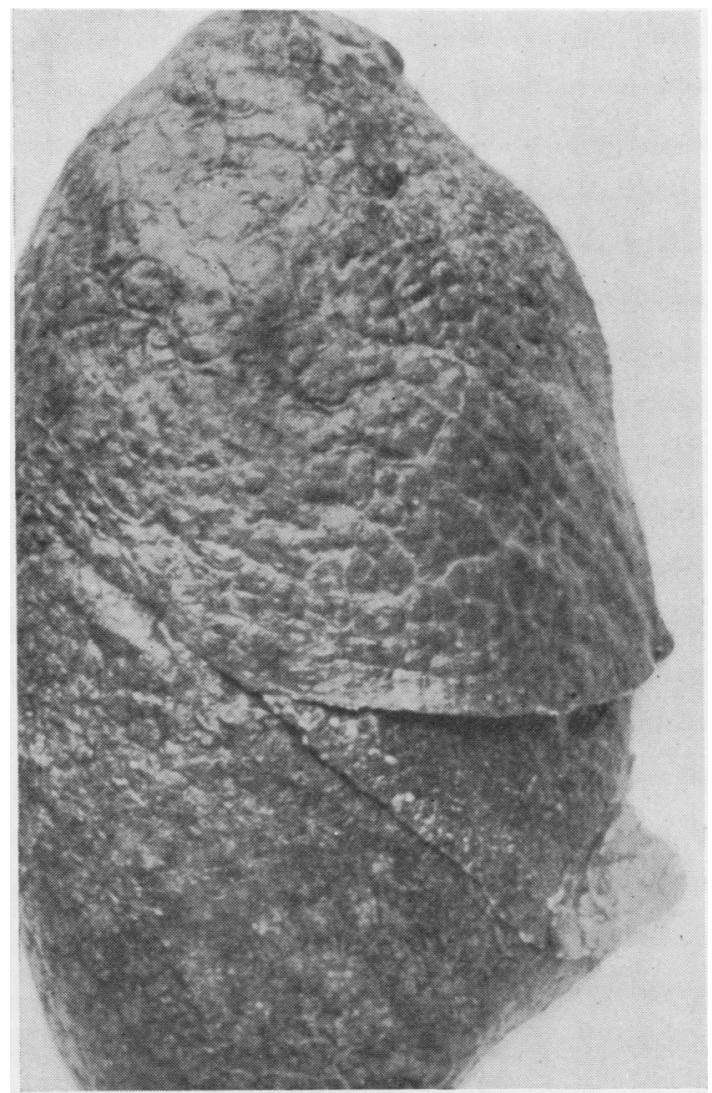

FIG. 1. Case 3. Nodular lung surface simulating a cirrhotic liver.

fibrosing alveolitis, and this diagnosis was made in all our cases. Lung biopsy or necropsy, however, revealed the muscular hyperplasia described in muscular 'cirrhosis' of the lung.

\section{CASE HISTORIES}

CASE 1 H. H., born in 1895. worked for seven years as a barrel maker, spent five years in the Army, cleaned railway engines for 17 years, and was a railway clerk for 20 years. About 1945 he began to notice shortness of breath, which slowly became worse and by 1957 was troublesome. He had to give up work in 1958 and was first seen by us in December of that year. He also gave a history of cough with scanty purulent sputum for eight years, but no previous chest radiograph had been taken.

On examination his general condition was good. $\mathrm{He}$ was cyanosed and dyspnoeic at rest. There were extensive crepitations over both lungs, and he had marked finger-clubbing. He said that his fingers had 


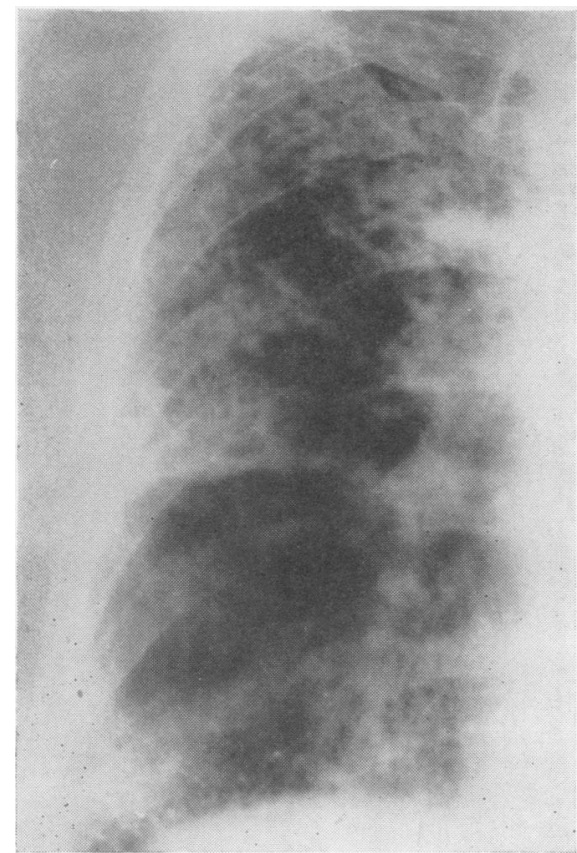

FIG. 2. Case 1. Radiograph of right lung showing honeycombing and diffuse shadowing.

been the same shape for many years. The haemoglobin level was normal, and the blood sedimentation rate was $62 \mathrm{~mm}$. in one hour (Westergren). His serum $\gamma$-globulin was $2 \cdot 7 \mathrm{~g}$. $/ 100 \mathrm{ml}$. The electrocardiogram showed tall $\mathbf{P}$ waves but no other abnormality. His chest radiograph showed diffuse shadowing throughout both lungs with honeycombing, most marked in the right upper lobe (Fig. 2). Three specimens of sputum were negative for tubercle bacilli on direct examination and culture.

$\mathrm{He}$ managed to get back to a light job intermittently but had to retire in October 1959 . $\mathrm{He}$ then had tachycardia at rest and a vital capacity of 1.65 l. and an F.E.V..$_{1.0}$ of 1.21 . He was treated with prednisolone, $15 \mathrm{mg}$. daily. Sputum cultures eventually produced a growth of acid- and alcoholfast bacilli. Two further specimens in January 1960 showed atypical acid-fast rods. The organism grew on culture and was identified as a photochromogenic mycobacterium in Runyon's group 1 .

He did not improve after starting treatment with prednisolone. It was continued, and P.A.S. and isoniazid were added in January 1960. Mycobacteria were not found in the sputum thereafter. He became more short of breath, and the left upper lobe became considerably more cystic. He died at home in September 1960, 15 years after the onset of dyspnoea.

During life it was considered that the mycobacterial infection was not the cause of his disease but that it was a secondary infection in damaged lungs.
Necropsy The body was that of a thin elderly maris The pleural sacs showed dense adhesions in the left with a few over the right apex. The trachea anf bronchi contained pus. Pleural adhesions obscure霖 the surface of the left lung, but the surface of the्户 right was nodular due to the presence of subpleuraf cysts. The left lung, sectioned post mortem, showet severe honeycombing in the upper lobe, includin the lingula, a few of the cysts measuring $3 \mathrm{~cm}$. in diameter. The cysts had a smooth inner lining and some intercommunicated. Confluent bronchoo pneumonia was present in the lower lobe, and ther was also some honeycombing subpleurally. The right lung was distended with $10_{\%}^{\circ}$ formalin, and whole-lung paper-mounted sections were prepared by the Gough-Wentworth technique. Honeycombing was

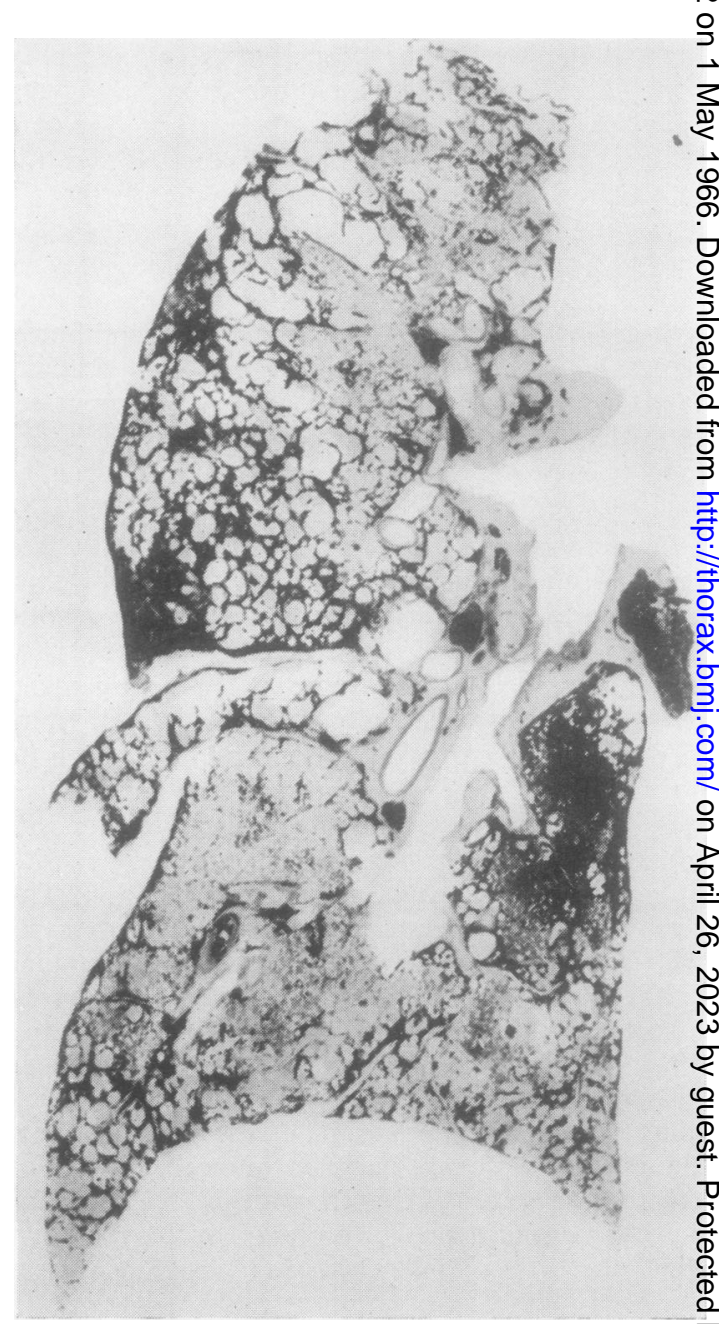

FIG. 3. Case 1. Right lung, coronal section showing severe honeycombing in all lobes. 


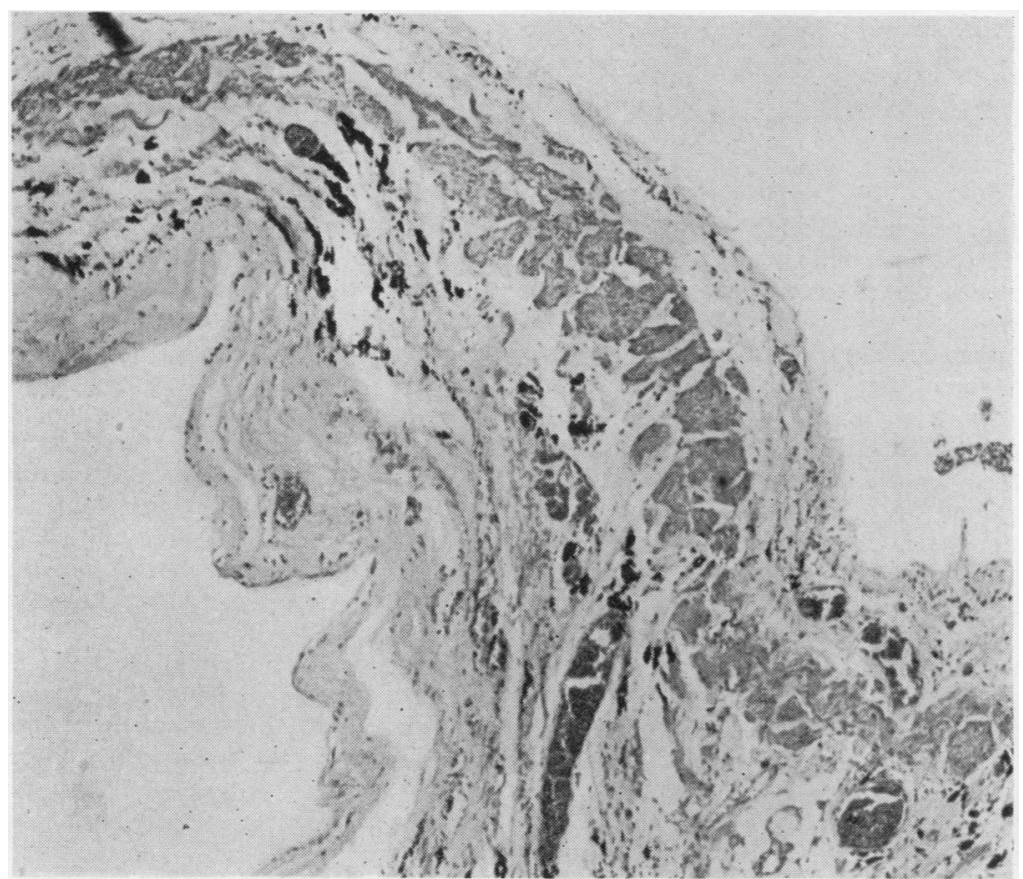

FIG. 4. Case 1. Wall of subpleural cyst containing a thick band of plain muscle. $H$. and $E$., $\times 50$.

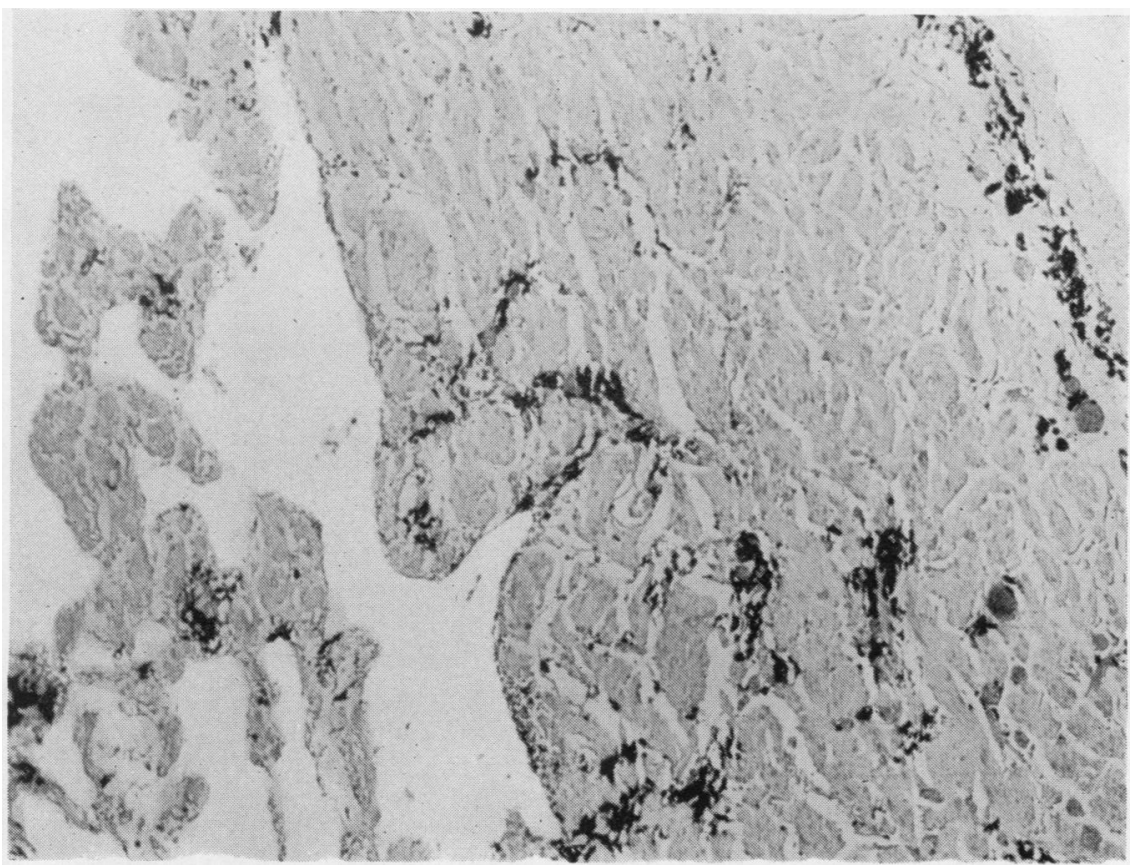

FIG. 5. Case 1. Subpleural overgrowth of plain muscle with diffuse muscular hyperplasia on left. Pleural surface, top right. Black areas are deposits of carbon. All the supporting frame-work is muscle. $H$. and $E$., $\times 50$. 
severe in the upper and middle lobes and in the basal half of the lower lobe (Fig. 3).

The heart showed generalized dilatation and slight right ventricular hypertrophy.

Histology of the lungs The most striking feature was the presence of abundant plain muscle around and between the cysts and under the pleura. The muscle often formed a distinct coat around the cysts, particularly subpleurally (Fig. 4). but it was also present in some areas as thick subpleural slabs unrelated to the honeycombing (Fig. 5). The collagenous stroma was variable in amount, but in most places it was overshadowed by the plain muscle. There was much cellular desquamation due to post-mortem autolysis, but in some areas a cubical or columnar epithelium lined the cysts. Chronic inflammatory cells were scanty. Towards the centres of the upper and lower lobes of both lungs the structure was essentially normal, apart from patchy areas of interstitial fibrosis. There was an acute bronchopneumonia, best developed in the lower lobes.

In two sections from the left lung a few small cysts were lined by chronic granulation tissue containing an occasional Langhan's giant cell. This was considered to be a tuberculoid type of reaction to the mycobacterium isolated from the sputum during life.

The pulmonary arteries showed marked medial hypertrophy and intimal fibrosis.
CASE 2 J.V.S. was born in 1905. In his early life he worked for seven years as a coal-miner and for seven years in an ironworks where there was a moderate amount of dust. He was not exposed to any important degree of dust or fumes thereafter. He first complained of dyspnoea and a slight dry cough in 1955. He was found to have a moderate degree of aortic stenosis. There was no previous history of rheumatic fever. The chest radiograph showed widespread nodulation in both lung fields. Dyspnoea became progressively worse. A tentative diagnosis of sarcoidosis was made in 1958, and treatment with corticosteroids was begun and continued until his death. This did not halt his steady downward course.

When admitted to hospital in August 1962 he had lost $4 \frac{1}{2}$ stones $(28.6 \mathrm{~kg}$.) in weight. He had tachypnoea at rest and mild finger-clubbing. There were coarse crackling sounds over both lungs. His blood pressure was $140 / 80 \mathrm{~mm}$. $\mathrm{Hg}$. A rough aortic systolic murmur was audible. There was no evidence of heart failure. Serial chest radiographs since 1955 had shown increased shadowing (Fig. 6). Radiographic evidence of calcification of the aortic valve was also found. The erythrocyte sedimentation rate was normal. Electrophoresis showed an increase in serum $\gamma$ globulin. The electrocardiogram showed left ventricular hypertrophy. His vital capacity was $1 \cdot 2 \mathrm{l}$, and he expired all this in one second. The total lung capacity was reduced to $2 \cdot 6$ litres. Gas mixing (helium) was complete in $1 \frac{3}{4}$ minutes. His arterial

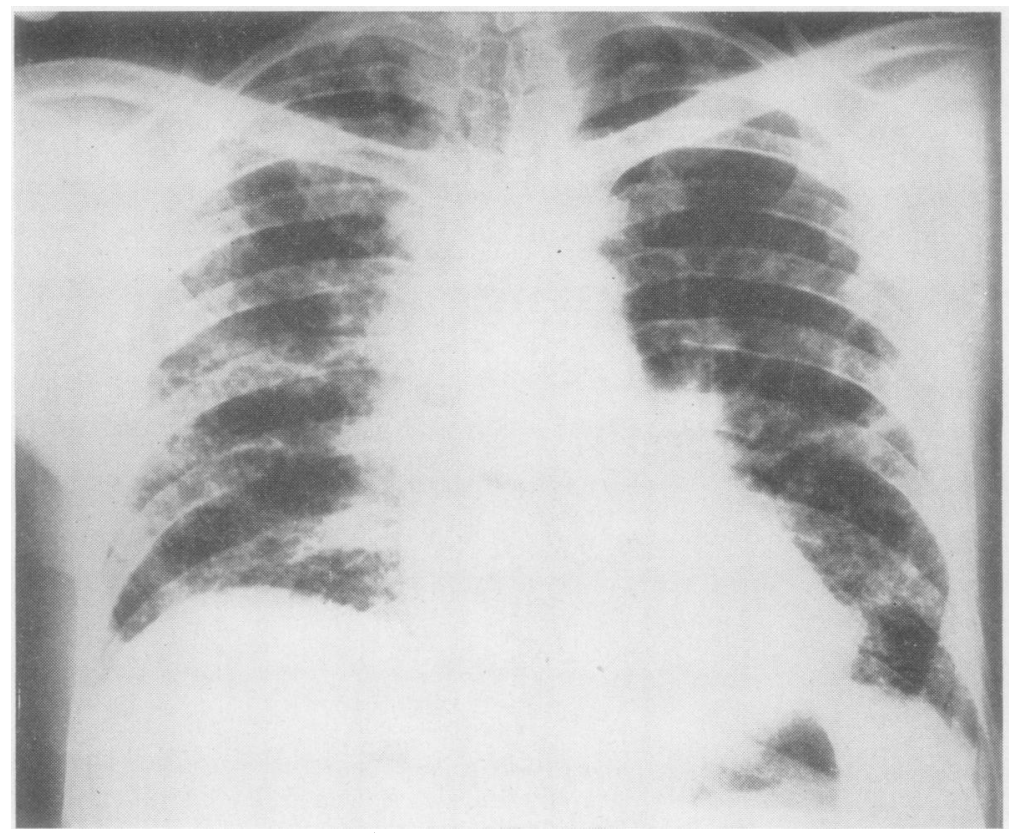

FIG. 6. Case 2. Chest radiograph showing widespread diffuse shadowing. 
oxygen saturation was $97 \%$ at rest and $86 \%$ on exercise. The arterial $p \mathrm{H}$ was 7.24 and the $\mathrm{PcO}_{2} 53$ $\mathrm{mm}$. $\mathrm{Hg}$. The carbon monoxide diffusing capacity was $6.5 \mathrm{ml} . / \mathrm{min} . / \mathrm{mm}$. $\mathrm{Hg}$ (steady-state method).

After thoracotomy biopsies of the right upper and lower lobes were taken. The pleura was free. The lung contracted considerably on opening the pleural cavity, and it felt fibrotic. Its surface was covered with small cysts.

His post-operative course was very stormy, due to a recurrent right pneumothorax. A remarkable degree of negative intrapleural pressure was noted, amounting to 60 to $75 \mathrm{~cm}$. of water. He died four weeks after operation.

Biopsy of lung The normal lung architecture was completely destroyed. The tissue consisted of small bronchi and cysts lined by bronchiolar epithelium, surrounded by thick sheaths of smooth muscle (Fig. 7). There was little fibrosis and no evidence of active inflammation.

Necropsy The body was that of a thin, middleaged man with clubbed fingers and a thoracotomy scar. There was an advanced calcific aortic stenosis with left ventricular hypertrophy and a recent fibrinous pericarditis with early organization. The lungs felt firm throughout. and subpleural cysts were prominent over the surfaces of the lower lobes. After perfusion with formalin, the lungs were sliced and showed honeycomb changes throughout the lower lobes, with smaller areas of honeycombing in the other lobes (Fig. 8).
Histology of lungs The honeycomb cysts were lined by bronchiolar epithelium and were often embedded in sheaths of hypertrophied smooth muscle. The pulmonary vessels showed marked medial hypertrophy, and areas of smooth muscle in zones of interstitial fibrosis often appeared to arise from vessel walls. The bronchi showed focal squamous metaplasia, and there were many spicules of ectopic bone in the interstitial fibrous tissue.

CASE 3 J. D., born in 1900, started work as a coalminer in 1914 and continued with underground work until he had to give up because of breathlessness in September 1963. A 35-mm. chest film in October 1957 was passed as normal then and on rescrutiny later. When first seen in October 1959 he gave a history of a slight cough and scanty sputum in winter for three or four years, and shortness of breath for a year. He could keep up with other people of his age when walking on the flat but not on hills. His general condition was good. He had spade-like fingers but no clubbing, and there were multiple fine crepitations over the lower half of both lungs. Other systems were normal. The chest radiograph showed fine pinhead nodulation throughout both lung fields, more marked at the bases (Fig. 9). The electrocardiogram was normal. A diagnosis of chronic diffuse fibrosing alveolitis was made.

He was kept under observation. A year later he was rather more short of breath, but there was no change in his chest radiograph. Breathing tests showed a restrictive impairment of ventilation.

He slowly deteriorated, having to take lighter jobs

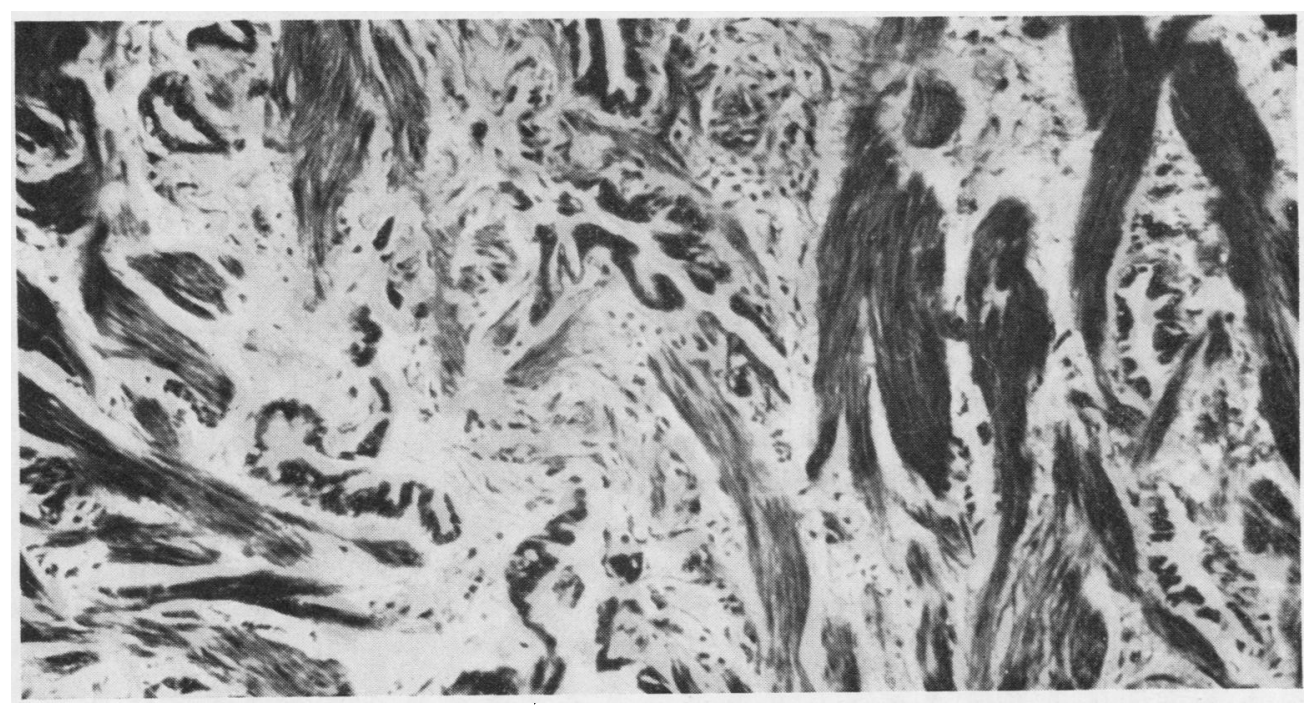

FIG. 7. Case 2. Lung biopsy. Irregular thick bands of plain muscle with epithelial-lined air spaces among them. $H$. and $E ., \times 125$. 


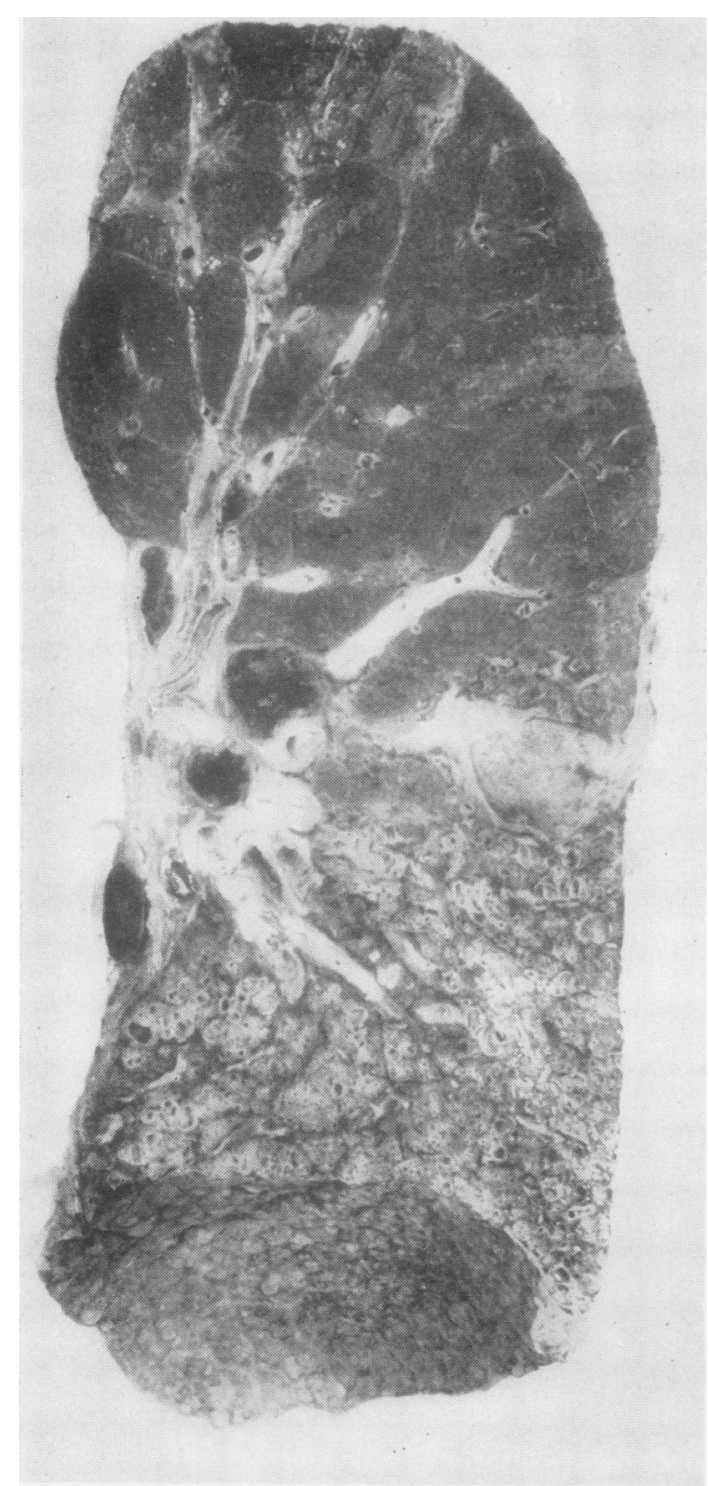

FIG. 8. Case 2. Left lung. Honeycombing in lower half, nodular basal surface.

and losing more time from work. There was a gradual increase in lung shadowing and a deterioration in lung function tests (Table II). He eventually agreed to undergo investigation in hospital.

When ad nitted in October 1963 his general condition was still good. His breathing was rapid at rest without any uheezing or prolongation of expiration. He was slightly cyanosed. There were still extensive fine crepitations over the lower half of both lungs but no other clinical abnormality. His haemoglobin

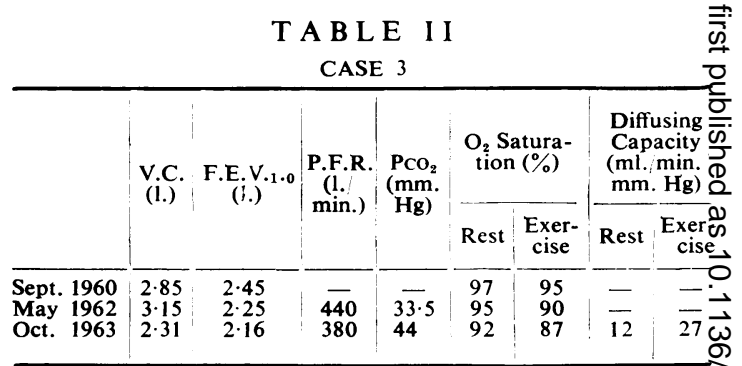

and white cell count were normal. The blood sedi $\vec{x}$ mentation rate was $20 \mathrm{~mm}$. in one hour (Westergren) and the serum $\gamma$-globulin $1 \cdot 7$ g. $/ 100 \mathrm{ml}$. Liver functioni tests were normal. The rheumatoid latex fixation tes on the serum was negative, but the Rose-Waaler tes $N$ was positive. The electrocardiogram showed that righ ventricular hypertrophy had developed since 1960.

At thoracotomy the left lung had a rather knobblys surface and felt firm throughout. There were some small subpleural cysts at the tip of the lingula. $A-$ biopsy included this area, together with deeper firm tissue.

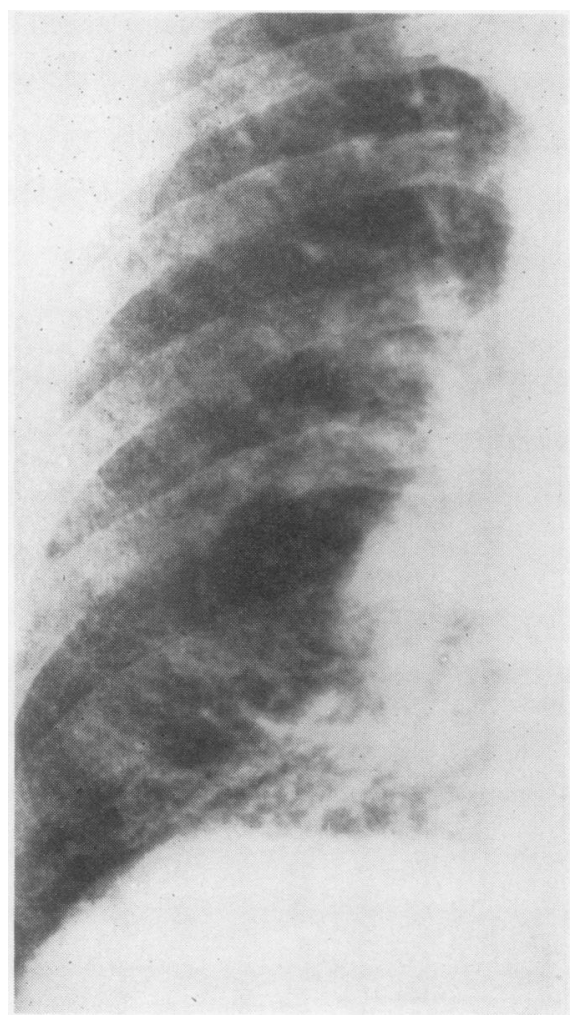

FIG. 9. Case 3. Radiograph of right lung showing fine nodulation. 


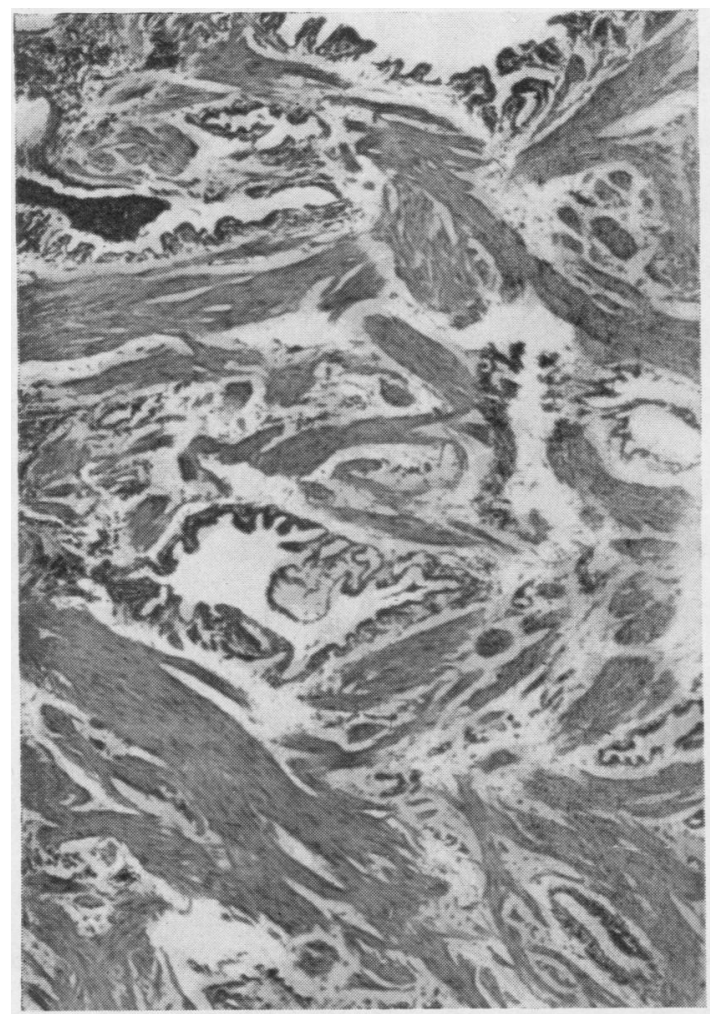

FIG. 10. Case 3. Lung biopsy. Marked excess of plain muscle among partially collapsed epithelial-lined cysts. $H$. and $E$., $\times 125$.

Lung biopsy The cysts were lined by cubical or columnar epithelium, and their walls were composed of a mixture of collagen and plain muscle. More deeply the same epithelial-lined air spaces were present, but they were collapsed. Around and between them were thick bands of plain muscle with very little connective tissue among them and only minimal evidence of inflammation (Fig. 10).

There were no post-operative complications, but he was too short of breath to return to work, and by December 1963 he could walk for 100 yards only. He was given prednisolone, $20 \mathrm{mg}$. daily. There was no improvement, and he was readmitted to hospital on 8 February 1964 with acute breathlessness, a troublesome cough, and mucoid sputum. His temperature was raised. Radiography revealed a moderately extensive right mid-zone consolidation. His sputum contained only normal flora. He was treated with oxygen, intravenous aminophylline, and oxytetracycline, and the dose of prednisolone was increased. After 36 hours he improved a little but died suddenly on 14 February, six years after the onset of shortness of breath.

Necropsy The body was that of a normally nourished elderly man. There was a healed thoracotomy scar over the left side. The right pleural sac was healthy; the left contained fibrous adhesions around the site of biopsy. The trachea and bronchi were filled with pus. Both lungs were distended with formalin and sectioned after fixation. The surface of each was nodular, and there were subpleural bullae in the right middle lobe (Fig. 1). Whole-lung paper-mounted sections showed extensive honeycombing in each lung involving almost the whole of each lower lobe and the right middle lobe and the anterior portion of the upper lobe (Fig. 11). The cysts varied from a few millimetres to $1.5 \mathrm{am}$. in diameter, the majority being about $5 \mathrm{~mm}$. In the lower lobe many of the cysts contained pus.

The heart weighed $390 \mathrm{~g}$. and showed generalized dilatation and moderate right ventricular hypertrophy.

Histology of the lungs In the areas of honeycombing there was a considerable excess of plain muscle around and between the cysts, many of which were lined by a single layer of epithelial cells. Where the cysts were small the bands of muscle usually

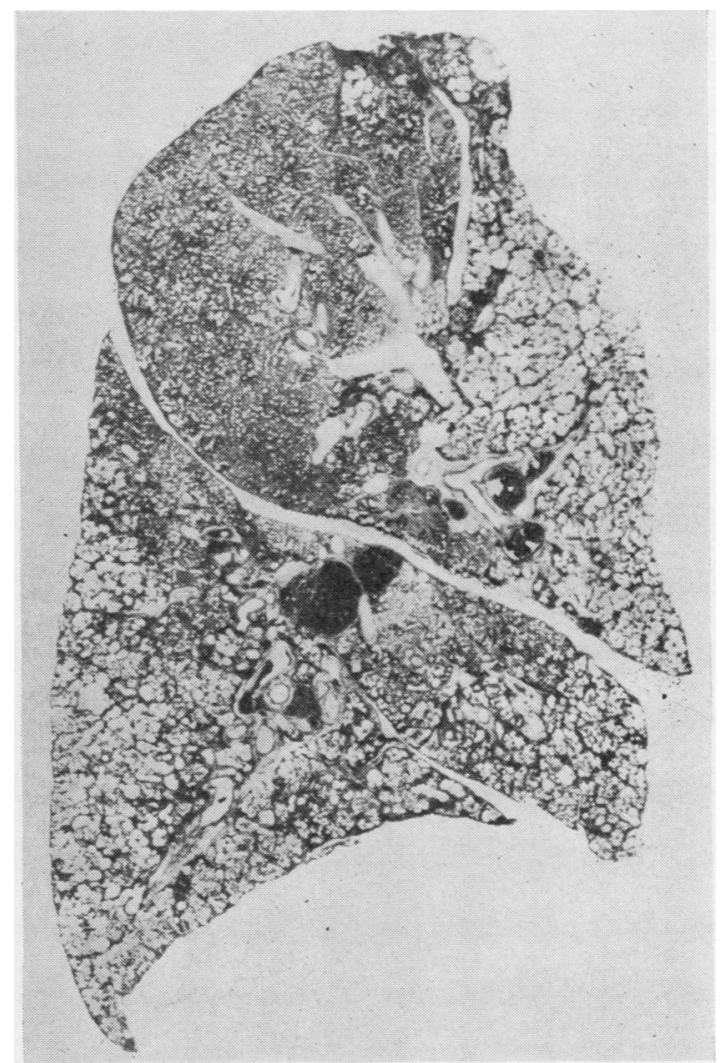

FIG. 11. Case 3. Right lung. Severe honeycombing in all areas. 


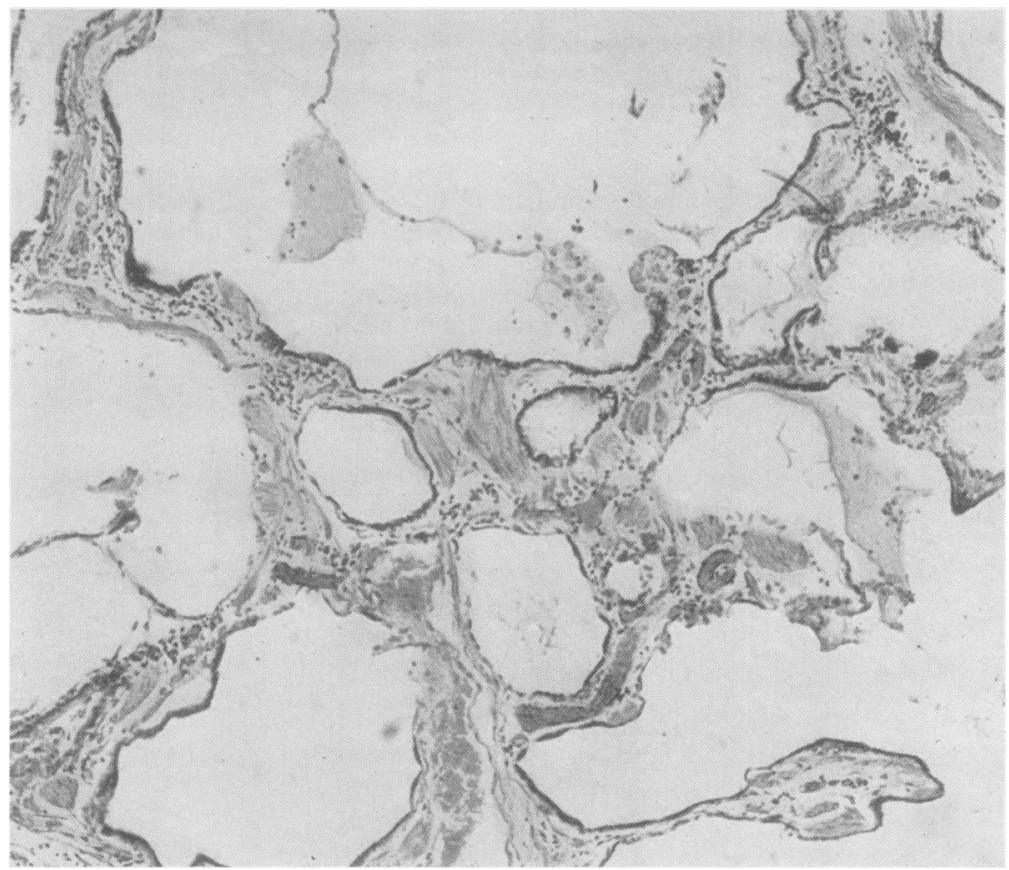

FIG. 12. Case 3. Diffuse over growth of plain muscle among cystic spaces of varying size. $H_{\omega}$ and $E$., $\times 50$.

formed a lattice work among them (Fig. 12). There were, however, many areas in both lungs where the cysts were enclosed by fibrous tissue and muscle was sparse. In areas free from honeycombing the histological features were those of chronic diffuse fibrosing alveolitis (Fig. 13). Acute bronchopneumonia was present in both lower lobes. The pulmonary arteries showed widespread muscular hyperplasia and sclerosis.
CASE 4 C. T., born in 1900, was admitted to hospitab in March 1964 because of pain in the chest and back and shortness of breath.

She gave a history of dysphagia in 1954, but no cause was found, and her symptoms soon improved A chest radiograph at that time was reported to be normal. She had been twice in hospital in 1958. com $\overrightarrow{F^{\circ}}$ plaining of pain in the back and the front of the chest with breathlessness. The back pain dated from

FIG 13. Case 3. Diffuse fibrosing alveolitis. Muscle inconspicuous. Terminal pneumonia. $H$. and $E$. $\times 50$.

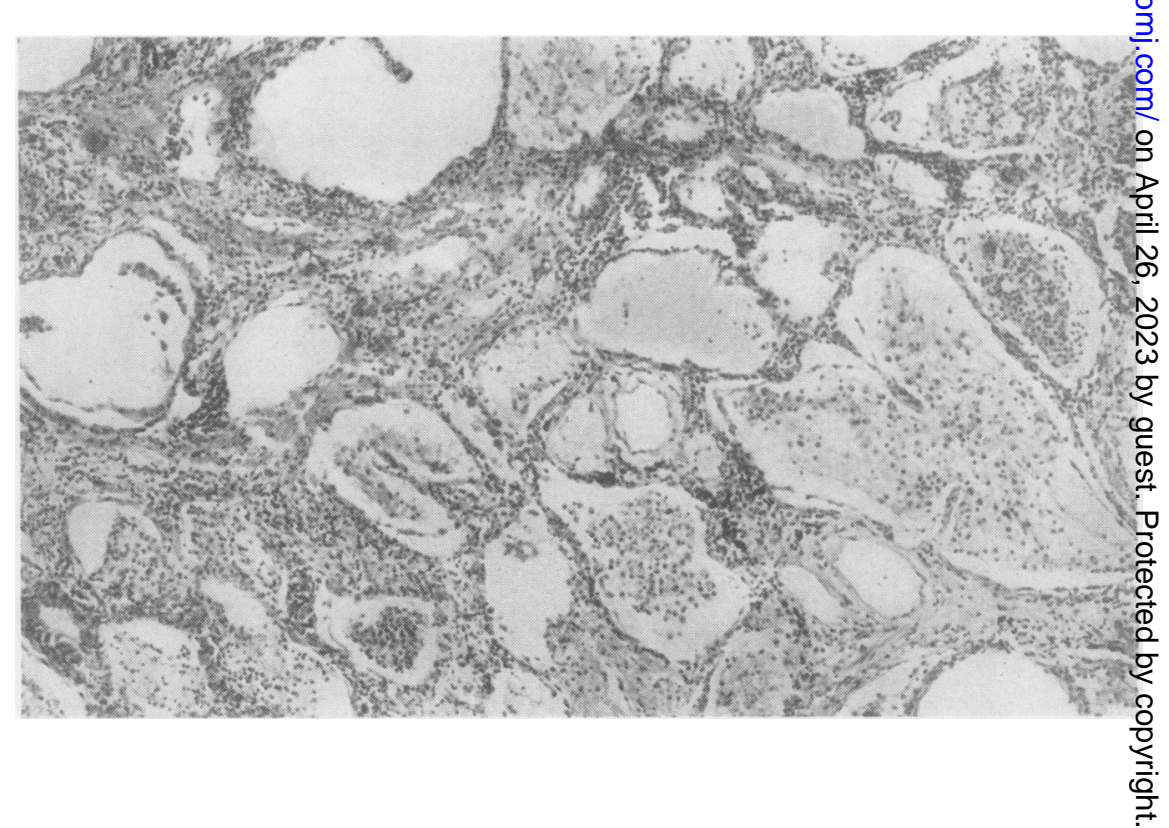


a fall some weeks earlier. Radiographs of the spine were normal, and that of the chest was reported to show some fibrosis or bronchiectasis. No firm diagnosis was made. Her symptoms continued, but she had little cough or sputum. She became worse in the autumn of 1963 and was admitted to hospital in March 1964.

She was well nourished. She had clubbing of the fingers, which had appeared about five years earlier. There were fine crepitations over the lower halves of both lungs, and she was dyspnoeic on slight exertion. She was tender over the lower thoracic spine. but there was no other clinical abnormality. The haemoglobin and white blood count were normal, and the erythrocyte sedimentation rate was $45 \mathrm{~mm}$. in one hour (Westergren).

She was found to have marked spinal osteoporosis with collapse of several thoracic vertebrae. The serum calcium was $10.3 \mathrm{mg} . / 100 \mathrm{ml}$., inorganic phosphate $3.6 \mathrm{mg}$. $/ 100 \mathrm{ml}$., alkaline phosphatase $20 \mathrm{~K}$.A. units/ $100 \mathrm{ml}$. The serum proteins were normal, and no Bence-Jones proteose was detected in the urine. On a low calcium diet the daily urinary calcium output over three days averaged $125 \mathrm{mg}$. She was considered to have post-menopausal osteoporosis and was put on a high calcium diet. The back pain improved and was not troublesome thereafter.

Her vital capacity was 1.1 1., F.E.V.1.0 0.991 , oxygen saturation $89 \%$ (ear oximeter), and carbon monoxide diffusing capacity $9.8 \mathrm{ml} . / \mathrm{min} . / \mathrm{mm}$. $\mathrm{Hg}$ (steady-state method). The electrocardiogram showed no abnormality. The rheumatoid latex fixation test was negative. The chest radiograph showed small lungs with high diaphragms. There was diffuse nodulation and some honeycombing (Fig. 14). Her previous radiographs were traced. Those taken in 1953 and 1954 showed nodulation in the left midzone and possibly some fine mottling in the remainder. The films taken in 1958 showed coarser nodulation throughout both lungs, more marked on the left side. The 1964 films showed further progress with shrinkage in lung volume and elevation of the diaphragms.

A diagnosis of chronic diffuse fibrosing alveolitis was made, but because of her age and the long duration of the disease it was anticipated that the lungs would show the changes of 'muscular cirrhosis'. It was considered that treatment with corticosteroids would not be of value, and she went home.

There was little change in her condition over the next few months, but by the end of 1964 she was more short of breath and hyperventilating at rest. She had also developed mild ankle oedema. She died fairly suddenly at home on 11 January 1965, nearly seven years after the onset of dyspnoea and 12 years after the first radiographic evidence of disease.

Necropsy The body was that of a normally nourished elderly woman with slight peripheral oedema. There were a few fibrous adhesions in both pleural sacs. Small amounts of mucopus were present in the trachea and bronchi. Both lungs were perfused with formalin. The posterior surfaces of both lower lobes

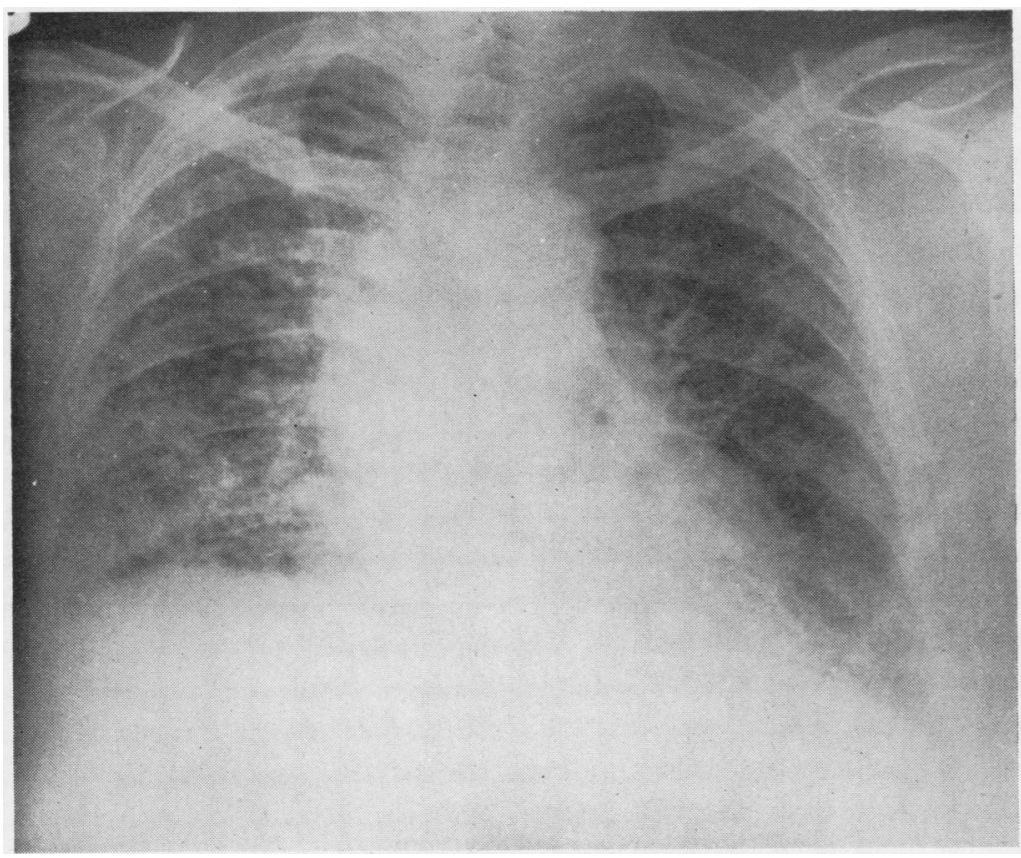

FIG. 14. Case 4. Chest radiograph showing diffuse nodulation and honeycombing. 
were nodular due to honeycombing, most marked in the posterior part of the left lower lobe (Fig. 15). The cysts measured up to $1.5 \mathrm{~cm}$. in diameter. The remainder of both lungs felt firm and fibrotic.

The heart showed slight right ventricular hypertrophy.

Histology of the lungs In the honeycombed areas the cysts were usually lined partly or wholly by epithelium, and their walls consisted of a mixture of fibrous tissue and plain muscle (Fig. 16). Elsewhere in both lungs the histological appearances were those of diffuse fibrosing alveolitis. Acute bronchopneumonia was present in both lower lobes, some of the cysts containing pus. The pulmonary arteries showed marked muscular hypertrophy and intimal fibrosis.

CASE 5 A. N., born in 1901, started work as a coalminer at the age of 14 years. He began to notice shortness of breath in 1960 and changed to a lighter job underground. He had little cough or sputum. His first chest radiograph was taken in May 1963. and he was investigated as a result.

His general condition was quite good. Apart from clubbing of the fingers there was no clinical abnormality. The chest radiograph showed some shift of the mediastinum to the right with apparent broadening of its upper part. There was diffuse mottling throughout both lungs, more marked on the right and at the left base (Fig. 17). The erythrocyte sedimentation rate was $94 \mathrm{~mm}$. in one hour (Westergren) and the serum $\gamma$-globulin $2 \cdot 8 \mathrm{~g} . / 100 \mathrm{ml}$. On various occa-

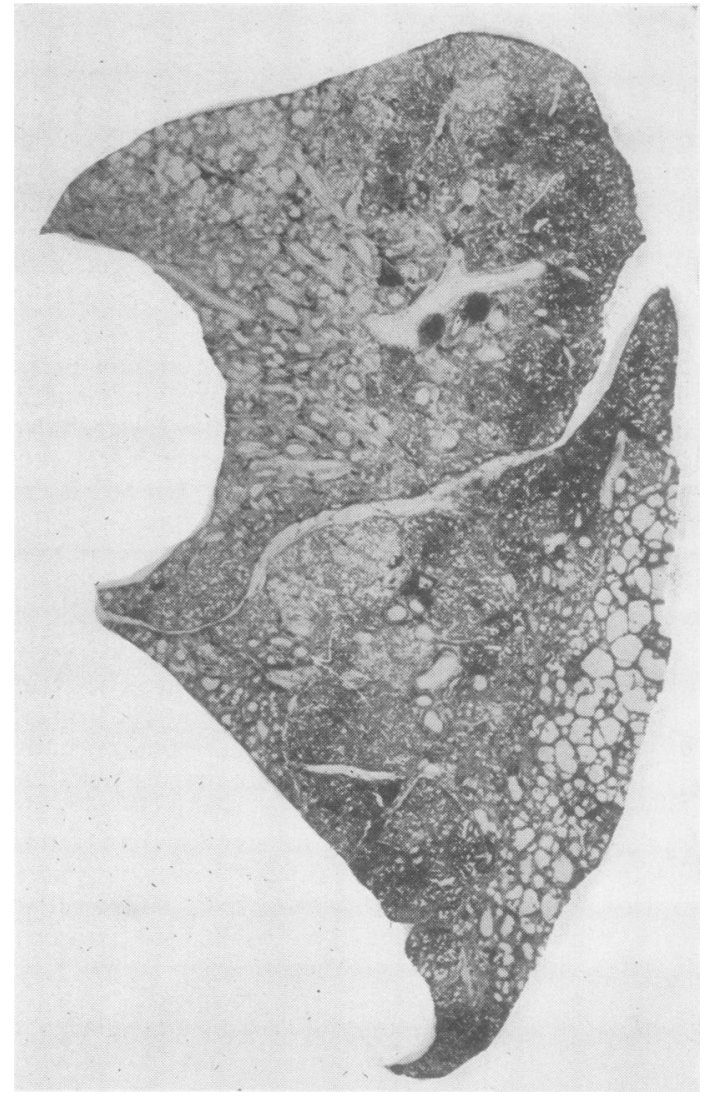

FIG. 15. Case 4. Left lung. Honeycombing restricted to posterior aspect of lower lobe.

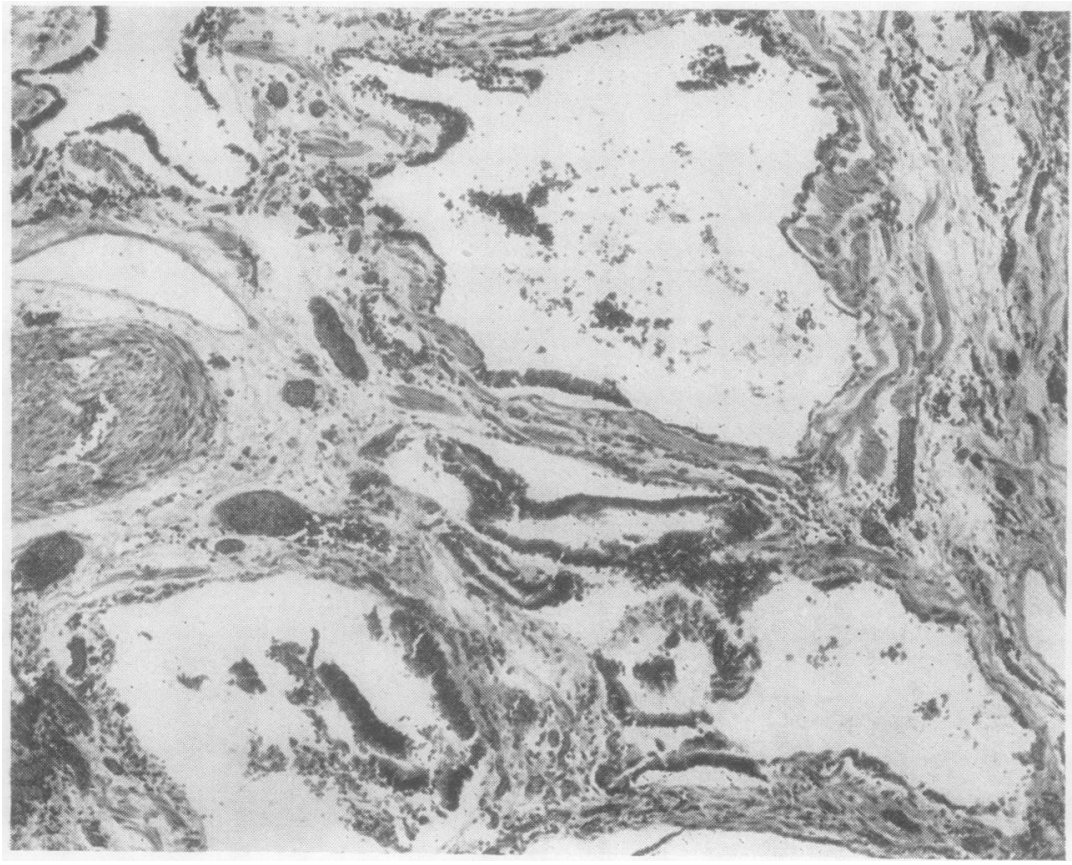

FIG. 16. Case 4. Muscular overgrowth around epithelial-lined cysts. Marked muscular hypertrophy and intimal fibrosis of pulmonary artery on left. $H$. and $E$., $\times 50$. 


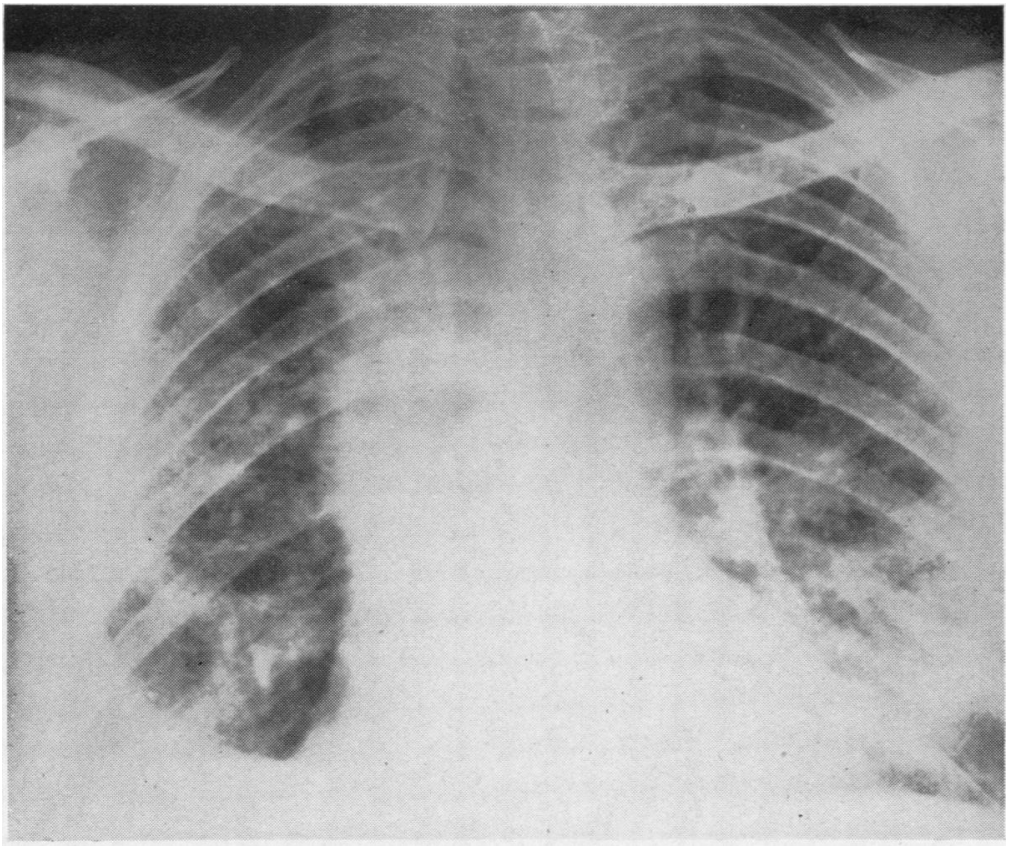

FIG. 17. Case 5. Chest radiograp't showing diffuse shadowing at both bases.

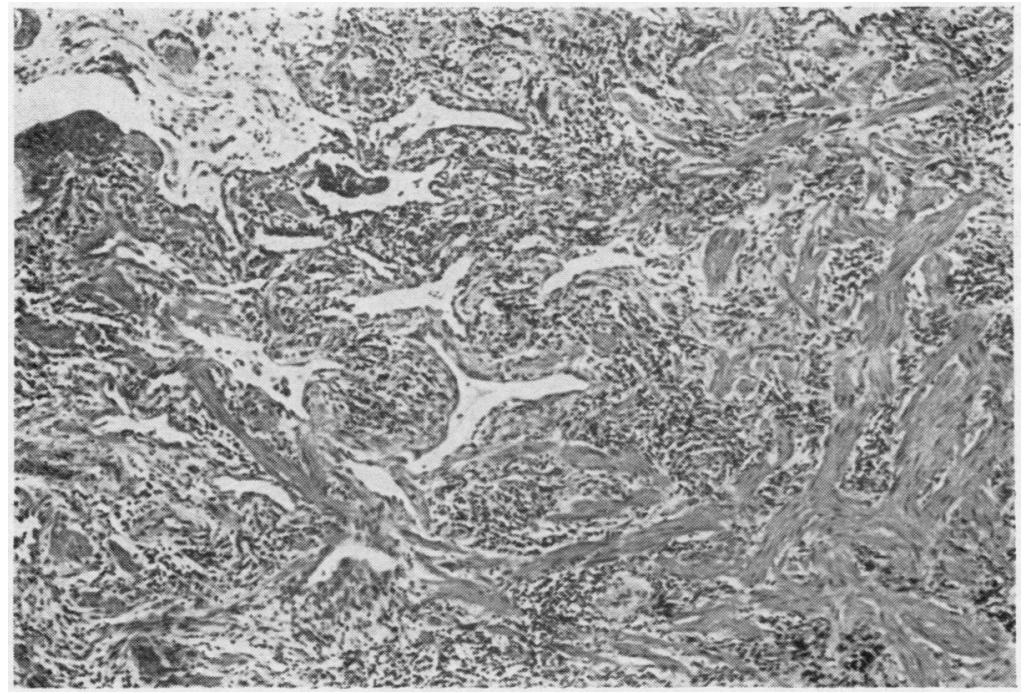

FIG. 18. Case 5. Lung biopsy. Collapsed air spaces embedded in fibrous tissue and plain muscle with chronic inflammatory cell infiltration. Masson, $\times 50$. 
sions the rheumatoid latex fixation test was positive once, weakly positive once, and negative once. The Rose-Waaler test was negative. Bronchoscopy showed no abnormality. The scalene lymph nodes contained only an excess of carbon. A right bronchogram showed that the sub-segmental bronchi reached out further to the periphery than usual, with narrowing of the unfilled peripheral zone. Ventilatory function tests showed a restrictive pattern, and the diffusing capacity was low.

He was too short of breath to go back to work, and in September 1963 a biopsy of the right middle lobe was done. The pleura was free. The lung was granular on palpation and difficult to inflate.

Lung biopsy A wedge of lung, 2.5 by 2 by $1 \mathrm{~cm}$., was taken with subpleural thin-walled cysts and firmer tissue more deeply. Histologically the cysts were lined by cubical epithelium, and their walls were composed of collagen fibres. The firmer tissue beneath the cysts was collapsed and contained air
T A B LE III

CASE 5

Diffusing $\overline{\frac{\sigma}{\sigma}}$

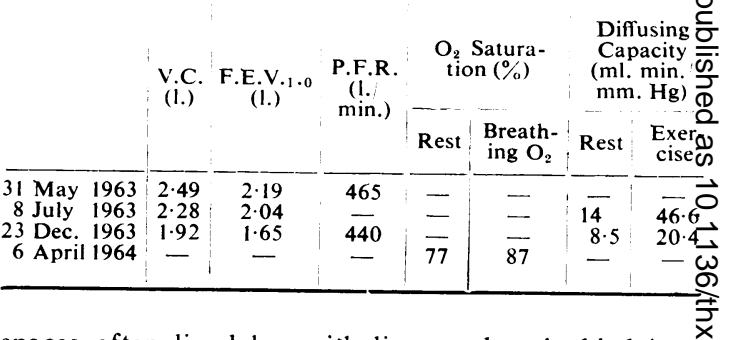

spaces often lined by epithelium and embedded in $\underset{\alpha}{ }$ framework of connective tissue and plain muscle infiltrated by chronic inflammatory cells. The muscle was distributed haphazardly and rarely appeared to be forming part of the walls of the air spaces (Fig $18)$.

Treatment with prednisolone was begun, but he continued to get more short of breath. Soon he was

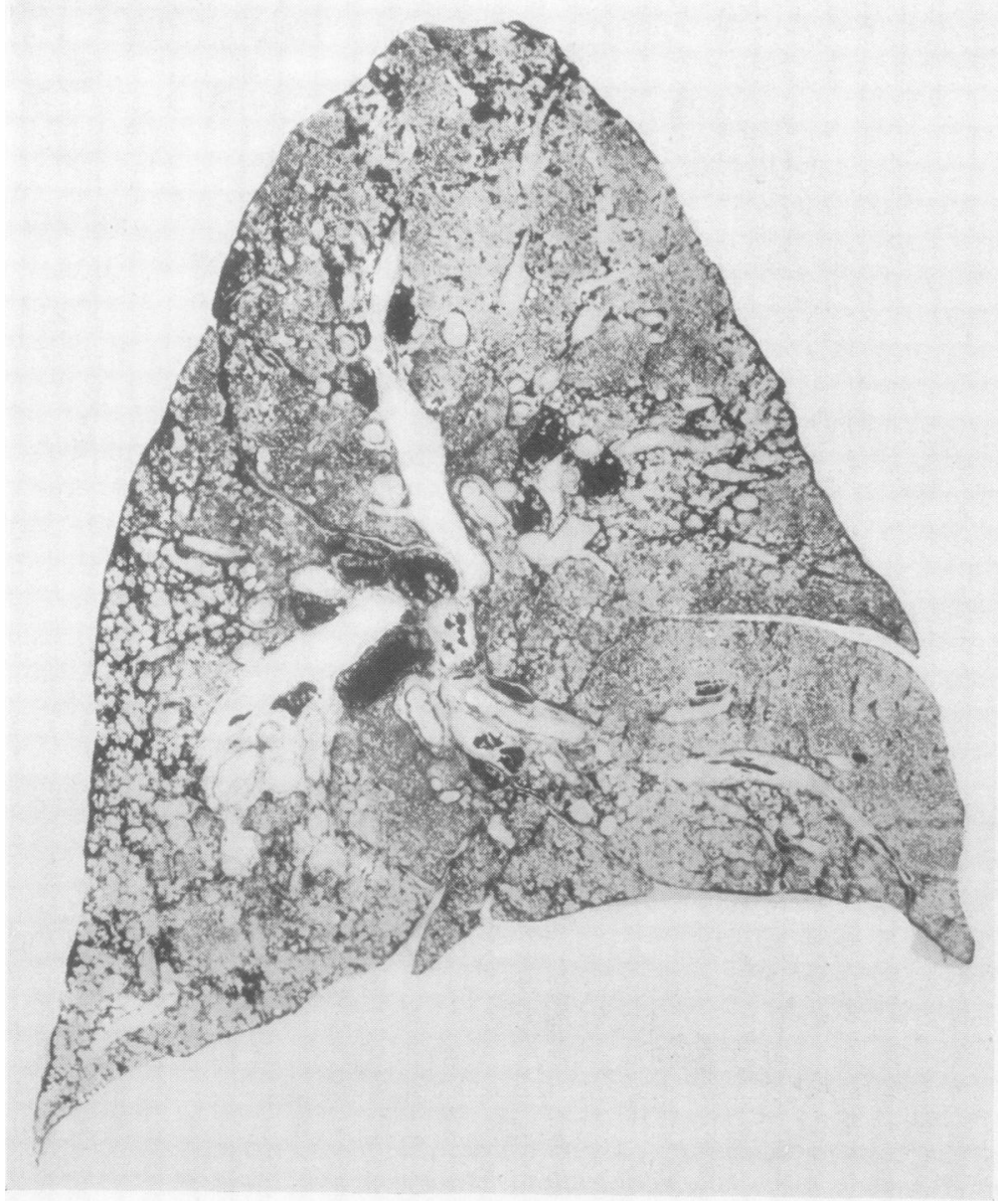

FIG. 19. Case 5. Right lung Slight honeycombing in upper ando lower lobes. 
dyspnoeic after walking 20 yards but was still comfortable at rest. Respiratory function tests showed fairly rapid deterioration (Table III). By November crepitations had developed at both lung bases. Treatment with prednisolone was tailed off in January. In April 1964 he was too short of breath to get out of bed and he died from respiratory insufficiency soon after, four years after the onset of shortness of breath.

Necropsy The body was that of a normally nourished elderly man. The pleural sacs were free, apart from adhesions around the site of lung biopsy. The trachea and bronchi contained mucopus. Both lungs felt firm, but the surfaces were not knobbly. They were distended with formalin and sectioned after fixation. They showed very early honeycombing in the posterior parts of both lower lobes and in the anterior part of the right upper lobe (Fig. 19). None of the cysts measured more than $5 \mathrm{~mm}$. in diameter. Elsewhere the lungs felt fibrotic.

The heart weighed $430 \mathrm{~g}$. and showed generalized dilatation with right and left ventricular hypertrophy. The aortic valve was bicuspid with early calcific stenosis.

Histology of the lung In all lobes the histological features were those of chronic diffuse fibrosing alveolitis. There was still considerable lymphocytic and histiocytic infiltration along with the increase in reticulum and collagen fibres in the wall of the air spaces (Fig. 20). In most areas plain muscle was not conspicuous, but it could be seen as small bundles or bands irregularly distributed throughout the fibrosed pulmonary framework. Occasionally were found large irregular sheaths of plain muscle (Fig. 21). Where honeycombing was present muscle became more prominent (Fig. 22), though nowhere reaching the proportions seen in cases 1 to 4 . Acute bronchopneumonia was present in the lower lobes. The pulmonary arteries showed muscular hyperplasia and sclerosis.

\section{DISCUSSION}

TERMINOLOGY The two most commonly used names for this condition are 'muscular cirrhosis of the lungs' and 'bronchiolar emphysema'. The former is a descriptive title for the condition and gives a fairly clear picture of firm, knobbly lungs with fibrosis and an excess of muscle, with destruction and distortion of normal tissue and architecture. It is, of course, only a descriptive title.

The authors choosing the title 'bronchiolar emphysema' or 'idiopathic diffuse bronchiolectasis'

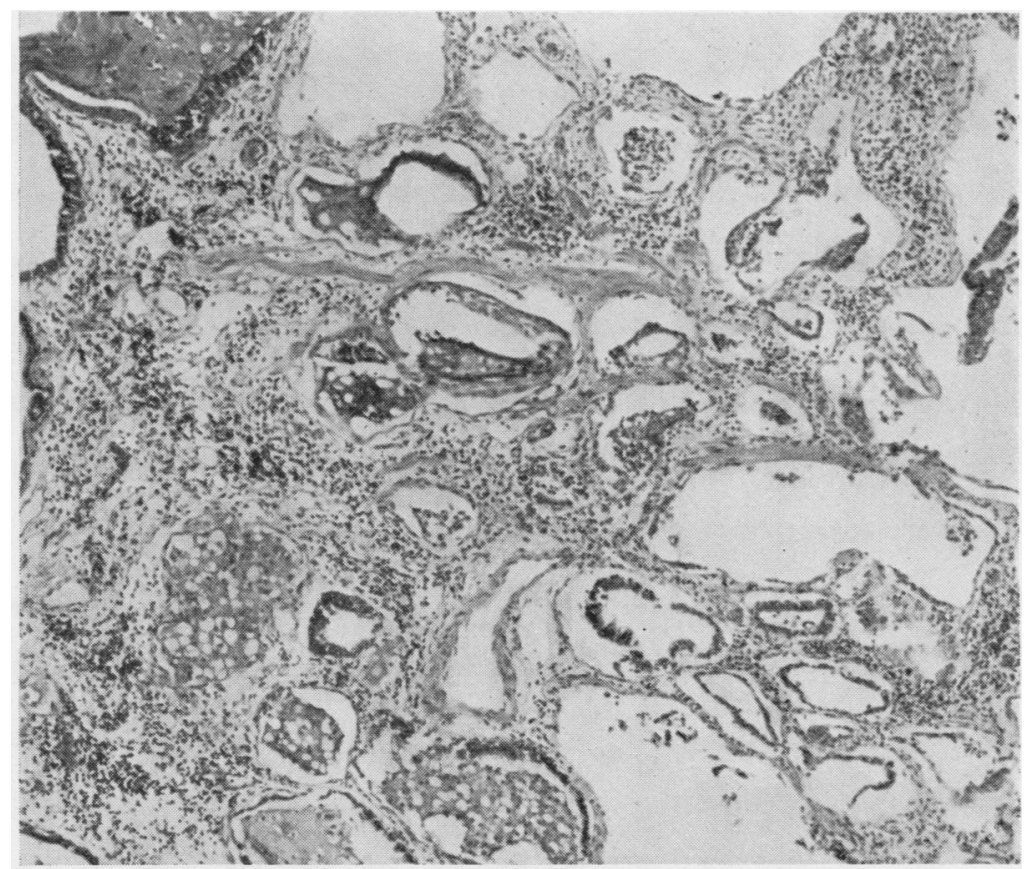

FIG. 20. Case 5. Diffuse fibrosing alveolitis with patchy muscular hyperplasia. Note long band of muscle running transversely above centre. $H$. and $E$., $\times 50$. 


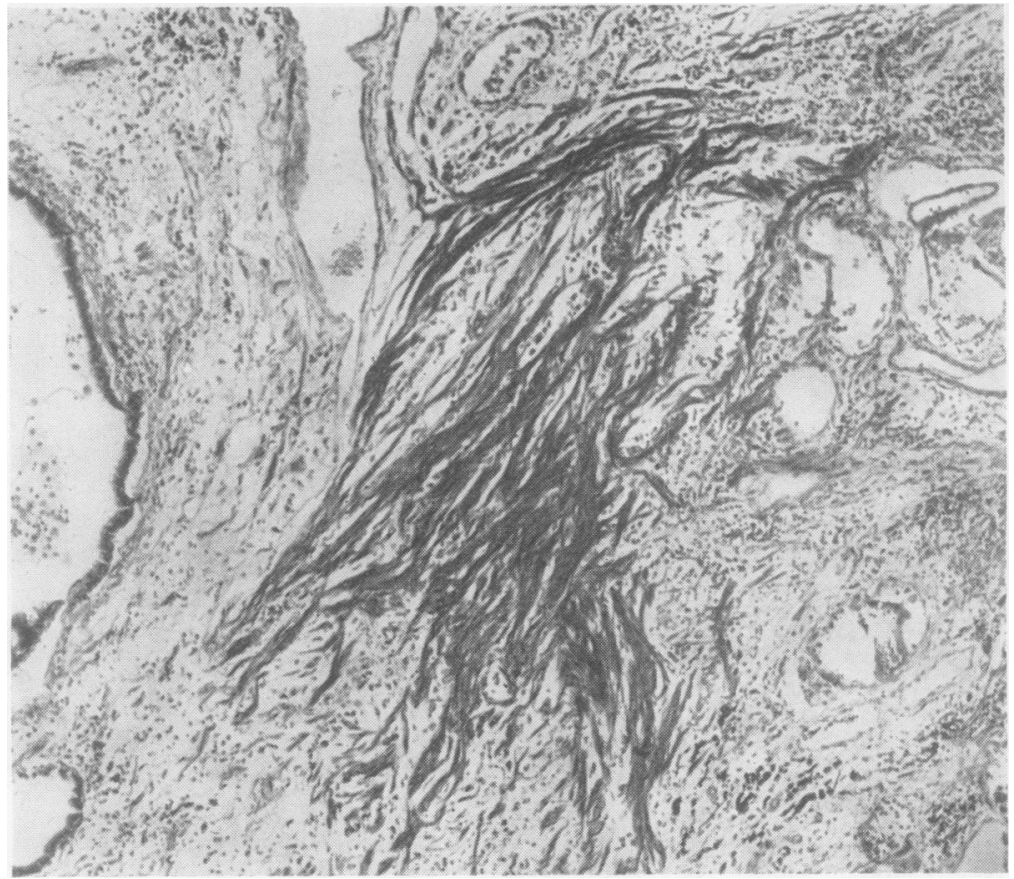

FIG. 21. Case 5. Marked overgrowth of muscle in fibrotic area. Masson, $\times 50$.

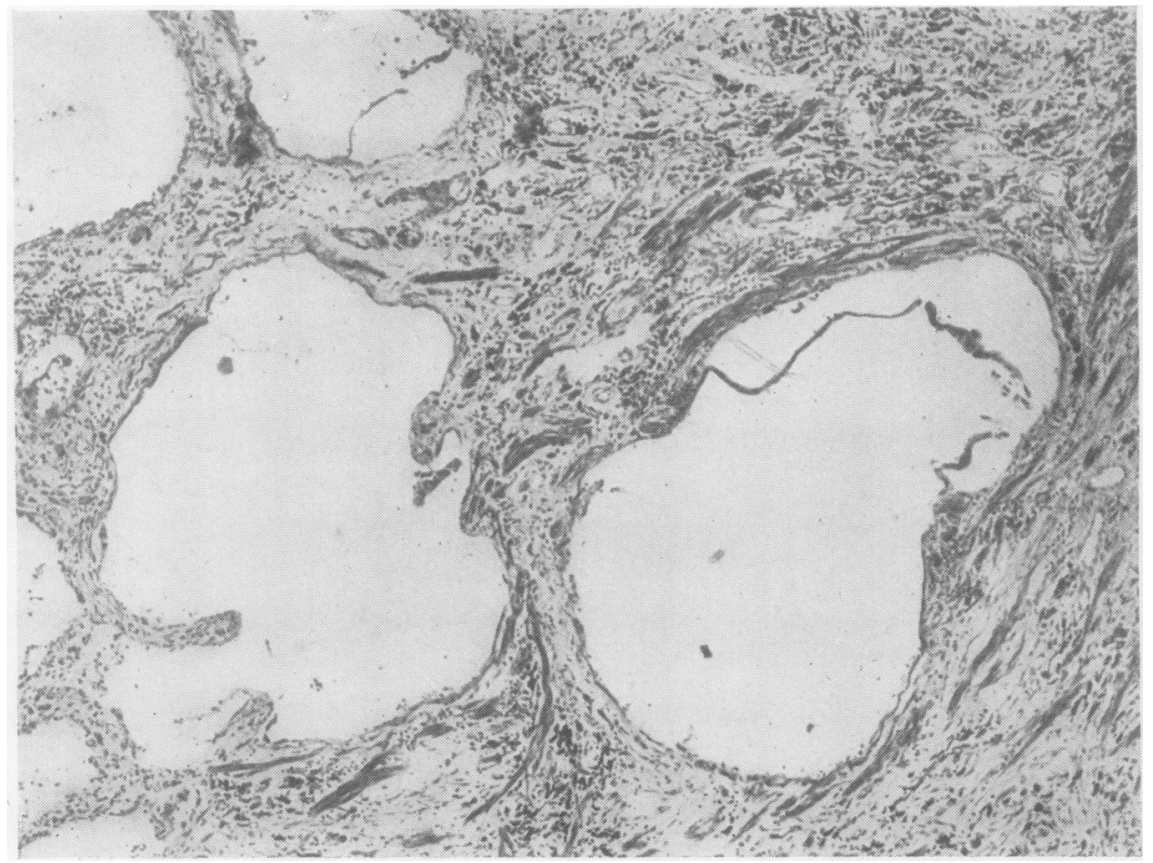

FIG. 22. Case 5. Patchy muscular hyperplasia in area of honeycombing. Masson, $\times 50$. 
(González-Licea and Pérez-Tamayo, 1963) have speculated on the origin of the cystic spaces in the lungs. In our opinion it is impossible to say whether these are terminal bronchioles, respiratory bronchioles, alveolar ducts, or epithelialized alveoli, or a mixture of all these. We consider that the most important change in the lungs is the obliteration and destruction of respiratory tissue at alveolar level and that the cystic changes are secondary to this. As this is only in a very minor way a "condition of the lung characterized by increase beyond the normal in the size of air spaces distal to the terminal bronchiole, either from dilatation or destruction of their walls' (Ciba Symposium definition of emphysema, 1959), it is incorrect to classify it as a form of emphysema. We do not agree with Siebert and Fisher (1957) that these cases show essentially the same physical and laboratory findings as do those with vesicular emphysema.

Because multiple small cysts are almost invariably a feature of this condition, it is one of the varieties of honeycomb lung. Oswald and Parkinson (1949) divided their cases of honeycomb lung into those with specific features and those without. Those with specific features were all young and had such diseases as xanthomatosis, biliary cirrhosis, tuberose sclerosis, or pituitary disorders. Their other cases were of uncertain aetiology, but spontaneous pneumothorax was common, whereas it has only once been reported in muscular cirrhosis of the lung. Heppleston (1956), in discussing the pathology of honeycomb lung, likewise divided the cases into those with and without specific features. To the specific features he added such conditions as berylliosis, giant-cell pneumonia, disseminated tuberculosis treated with drugs, and scleroderma. In the cases without specific features he noted that the lungs often contained an excess of smooth muscle in greater or lesser degree. 'Muscular cirrhosis' of the lungs is therefore a non-specific form of honeycomb lung in which hyperplasia of smooth muscle is so marked as to be very prominent and to excite comment.

Heppleston in his series also classified one case as primary leiomyomatosis. We have not seen such a condition and cannot say whether it exists as an entity independent of tuberose sclerosis. Heppleston's patient had chylous ascites and pleural effusion, and this condition may be related to that described by Fraimow and Cathcart (1962) as 'intrathoracic angiomyomatous hyperplasia with chronic chylothorax and retrop?ritoneal pseudocystic angiomyomatous hyperplasia'.
Rosendal's (1942) patient included in Table I may have been an example of primary leiomyomatosis because the lymph nodes were involved.

PATHOGENESIS A variety of theories have been put forward to explain the development of this condition. Early authors suggested an inflammatory cause. Siebert and Fisher (1957) put forward an ingenious theory that it is a form of hypertrophic emphysema, but that hypoplasia of the distal respiratory unit caused the emphysema to be bronchiolar in location rather than 'vesicular'. González-Licea and Pérez-Tamayo (1963) consider the condition to be primarily a selective dilatation of the terminal bronchioles, a sort of no-man's-land between bronchiectasis and emphysema. They suggested idiopathic diffuse bronchiolectasis as the most appropriate name. Fraimow and Cathcart (1962), however, speculated that the earliest change might be that of interstitial pulmonary fibrosis (diffuse fibrosing alveolitis) and pneumonitis.

We have already indicated that our cases and those described in the literature are indistinguishable on clinical, radiological, and physiological grounds from diffuse interstitial pulmonary fibrosis or chronic diffuse fibrosing alveolitis (Scadding, 1964 ; Gough, 1964). Our cases 1 to 4 showed histological evidence in parts of both lungs, generally away from the honeycombed areas, of diffuse interstitial pulmonary fibrosis. Case 5, of shorter duration, was considered during life to be a further example of muscular cirrhosis of the lungs on the basis of the lung biopsy which contained a considerable amount of muscle. Necropsy, however, showed it to be an example of chronic diffuse fibrosing alveolitis with patchy muscular overgrowth. We have reviewed necropsy lung sections from other cases of chronic diffuse fibrosing alveolitis and have found evidence of muscular hyperplasia in several, particularly where honeycombing has occurred. From the sheer amount of muscle present in the cases of muscular cirrhosis we cannot accept that this is merely a condensation of existing muscle (Livingstone, Lewis, Reid, and Jefferson, 1964) due to the honeycombing, but consider it must be due to a real increase from hyperplasia.

The normal lung does contain a considerable amount of muscle in the walls of its blood vessels, bronchi, and bronchioles, including the respiratory bronchioles. Fine interweaving bands are also present in the alveolar ducts but not in the walls of the alveoli themselves. A few muscle fibres may also be present in the walls of the large subpleural 
lymphatics (Heppleston, 1963). Liebow, Loring, and Felton (1953) stressed the difficulty of identifying the source of the increased muscle which is sometimes a feature of various chronic pulmonary diseases, and serial sections are often needed. We have occasionally identified abnormal bands of muscle arising from pre-existing bronchiolar muscle or hypertrophied blood vessels, but in most instances it is impossible to define the source. The origin of the cysts in the honeycombed area also gives rise to doubt. Some are almost certainly distended bronchioles, but others may well be greatly enlarged alveolar ducts or even alveoli, particularly when the muscle forms a lattice-work among the cysts rather than a definite wall around each (Fig. 12).

Some degree of muscular hyperplasia appears to us to be a common accompaniment of chronic diffuse fibrosing alveolitis. A study of a rapidly fatal case of three months' duration has shown tiny sheaths of proliferating muscle cells in the thickened and oedematous walls of the air spaces. Much of this proliferating muscle appears to be arising from respiratory bronchioles and alveolar ducts, and it is possible that at least some of the excess muscle in cases of muscular cirrhosis has originated from these sites.

The average age at the onset of dyspnoea is about the same in muscular cirrhosis as in chronic diffuse fibrosing alveolitis. The range for cases in Table I is 25 to 78 years with, as far as can be determined, a mean of 52 years and a median of 52.5 years. In the 45 cases of 'diffuse interstitial pulmonary fibrosis' reported by Livingstone et al. (1964) the range was 20 to 78 years, with a mean of 50.5 years and a median of 55 years. The duration of the disease tends to be longer in 'muscular cirrhosis'. Based on symptoms, it was five years or more in 15 out of $30(50 \%)$, compared with 15 out of $45(33 \%)$ in Livingstone's series. In contrast to Scadding's (1960) findings, Livingstone and his colleagues found that long survival was associated with an early onset and a short life with a later onset. Of the 26 who developed symptoms at the age of 50 or over, $16(62 \%)$ were dead in less than three years and only five $(19 \%)$ survived four years. This compares with three out of $18(17 \%)$ dead in less than three years among those with muscular cirrhosis who developed symptoms at the age of 50 or more. Twelve $(67 \%)$ of these survived for over four years. It seems that if a person develops chronic diffuse fibrosing alveolitis at the age of 50 or more and survives longer than three years he tends to end up with muscular cirrhosis.
Cases of chronic diffuse fibrosing alveoliti卷 which run a short course do not as a rule show honeycombing. Many of the more chronic cases듬 however, do show this as the main feature a necropsy, though the relationship between dura tion of disease and honeycombing is not clear-cut $\stackrel{\rho}{a}$ The cysts occupy in the main the peripheral basa? and lateral areas, the central and apical areaș being spared (Gough, 1965). Except in case $1, \overrightarrow{-}$ this is also the distribution in our patients, theू posterior parts of the lower lobes being mos heavily involved. It is almost certainly true that chronic diffuse fibrosing alveolitis is the common $\rightarrow$ est cause of honeycomb lung, and many paper on the pathology of the former mention fibro $N$ muscular hyperplasia as a common feature, e.g.o Herbert, Nahmias, Gaensler, and MacMahon? (1962).

In our opinion, 'muscular cirrhosis of the lung and 'bronchiolar emphysema' are descriptive terms for variants of chronic diffuse fibrosing alveolitis. A long duration, when the condition appears in the elderly, seems to provide a greater opportunity for honeycombing and muscula hyperplasia to develop. A satisfactory descriptive title for this condition would be a chronic diffuse fibrosing alveolitis with muscular hyperplasia an honeycombing".

It seems doubtful if exposure to coal and othe $\vec{\beta}$ dust plays a part in determining this variation of diffuse fibrosing alveolitis. Though three of. our patients were coal-miners this mas easily have occurred by chance because a cono응 siderable proportion of our patients are sळ̋ employed. One of Siebert and Fisher's (1957 patients was a coal-miner and the one describeç by Brun, Perrin-Fayolle, Cassan, and Tommass (1963) also had some dust exposure. Bowermañ and Towbin's (1964) patient was a welder. Fouro teen out of the 30 patients in Table I, however are women, so it is unlikely that exposure to duse is very important. Even so, Chatgidakis (1960\% found that nodular muscular hyperplasia was common finding in the lungs of South Africa gold- and coal-miners.

In two of our three patients in whom the test? were done, the rheumatoid latex fixation test of the Rose-Waaler reaction were positive. Suc findings are becoming increasingly recognized as features in patients with chronic diffuse fibrosing alveolitis who never develop rheumatoid arthriti (Turner-Warwick and Doniach, 1965; MacKaP and Ritchie, 1965). Two of our patients also ha\& aortic stenosis, but this was only of clinical signe ficance in one: it does not seem to have beep 
recorded in other published cases and may be a coincidence.

TREATMENT Four of our patients were treated with corticosteroids without benefit. The result was the same in two other cases recorded in the literature (cases 2 and 4 of Fraimow and Cathcart, 1962). With such well established and irreversible changes, this is only to be expected.

\section{SUMMARY}

The literature on 'muscular cirrhosis of the lungs' and 'bronchiolar emphysema' has been reviewed. The patients are, in the main, middle-aged or elderly people with slowly progressive dyspnoea. The chest radiographs show diffuse fibrosis and at necropsy the lungs are honeycombed. Hyperplasia of smooth muscle is conspicuous. They show no evidence of such conditions as eosinophilic granuloma, tuberose sclerosis, scleroderma, or other specific conditions associated with honeycombing.

Five new cases are described. Clinically, radiographically, and physiologically they displayed the features of chronic diffuse fibrosing alveolitis. They deteriorated slowly and died from four to 15 years after the onset of dyspnoea. Pathologically they had honeycombing of the lungs with excess muscle in the cystic areas and the histological features of diffuse fibrosing alveolitis elsewhere. Four were classical examples of 'muscular cirrhosis' of the lungs. In the fifth, that diagnosis was made on the lung biopsy, but post-mortem examination showed that the muscular overgrowth was patchy and not nearly as well developed as in the others, the overall picture being that of chronic diffuse fibrosing alveolitis.

The increase in plain muscle in these cases is real and not due merely to condensation of lung tissue.

'Muscular cirrhosis of the lungs' and 'bronchiolar emphysema' are not separate entities but descriptive terms, the latter being a particularly unfortunate one. They are variants of chronic diffuse fibrosing alveolitis, related to a late onset and long duration of the disease.

We acknowledge the help of many colleagues who have assisted and given information. For most of the photographs our thanks are due to Mr. A. G. Sylvester and the staff of the Photographic Unit of the Sheffield Regional Hospital Board. We are grateful to Miss B. Buck for secretarial work.

\section{REFERENCES}

Bowerman, D. L., and Towbin, M. N. (1964). Bronchiolar emphysema: its significance in industrial medicine. Dis. Chest, 46, 349.

Brun, J., Perrin-Fayolle, M., Cassan, G., and Tommasi, M. (1963). La cirrhose musculaire lisse (léiomyomatose) des poumons empoussières. J. franc. Méd. Chir. thor., 17, 325 .

Burman, S. O., and Kent, E. M. (1962). Bronchiolar emphysema (cirrhosis of the lung). J. thorac. cardiovasc. Surg., 43, 253.

Calma, I. (1941). Cystic emphysema of the lungs with interstitial sclerosis. Brit. J. Tuberc., 35, 40.

Chatgidakis, C. B. (1960). Nodular muscular hyperplasia in the lungs of South African miners. Arch. industr. Hlth, 21, 160.

Ciba Guest Symposium (1959). Terminology, definitions, and classification of chronic pulmonary emphysema and related conditions. Thorax, 14, 286.

Delarue, J., Paillas, J., Paley, P., Daumet, P., and Daussy, M. (1960). Insuffisance respiratoire progressive, emphysìme bulleux et leiomyomatose pulmonaire diffuse. J. franc. Méd. Chir. thor., 14, 761 .

Fraimow, W., and Cathcart, R. T. (1962). Clinical and physiological considerations in pulmonary muscular hyperplasia. Ann. intern. Med., 56, 752.

Gonzalez-Angulo, A. (1962). Diffuse bilateral peribronchiolar and interstitial muscular hyperplasia associated with bronchiolar dilatation (bronchiolar emphysema). Amer. Rev. resp. Dis., 86, 256.

Gonzáles-Licea, A., and Pérez-Tamayo, R. (1963). Idiopathic diffuse bronchiolectasis-so-called bronchiolar emphysema. Amer. J. clin. Path., 40, 157.

Gough, J. (1964). Fibrosing alveolitis. Brit. med. J., 2, 818.

(1965). Pathological changes in the lungs associated with cor pulmonale. Bull. N.Y. Acad. Med., 41, 927.

Heppleston, A. G. (1956). The pathology of honeycomb lung. Thorax, 11, 77.

- (1963). Lung muscle. Lancet, 1, 1107.

Herbert, F. A., Nahmias, B. B., Gaensler, E. A., and MacMahon, H. E. (1962). Pathophysiology of interstitial pulmonary fibrosis. Arch. intern. Med., 110, 628.

Hirshfield, H. J., Krainer, L., and Coe, G. C. (1962). Cystic pulmonary cirrhosis (bronchiolar emphysema). Dis. Chest, 42, 107.

Jerry, L. M., and Ritchie, A. C. (1964). Bronchiolar emphysema. Canad. med. Ass. J., 90, 964.

Liebow, A. A., Loring, W. E., and Felton, W. L. (1953). The musculature of the lungs in chronic pulmonary disease. Amer. J. Path., 29,885 .

Livingstone, J. L., Lewis, J. G., Reid, L., and Jefferson, K. E. (1964). Diffuse interstitial pulmonary fibrosis. Quart. J. Med., 33, 71.

McAdams, G. B. (1961). Bronchiolar emphysema. Arch. intern. Med., 108, 279.

MacKay, I. R., and Ritchie, B. (1965). Diffuse fibrosing alveolitis (diffuse interstitial fibrosis of the lungs): two cases with auto. immune features. Thorax, $20,200$.

Oswald, N., and Parkinson, T. (1949). Honeycomb lungs. Quart. J. Med., 18, 1.

Ravines, H. T. (1960). Bronchiolar emphysema of the lungs. Arch. Path., 69, 554.

Rosendal, T. (1942). A case of diffuse myomatosis and cyst formation in the lung. Acta radiol. (Stockh.), 23, 138.

Rubenstein, L., Gutstein, W. H., and Lepow, H. (1955). Pulmonary muscular hyperplasia (muscular cirrhosis of the lungs). Ann. intern. Med., 42, 36.

Scadding, J. G. (1960). Chronic diffuse interstitial fibrosis of the lungs. Brit. med. J., 1, 443. (1964). Fibrosing alveolitis. Ibid., 2, 686.

Schaffner, F. (1959). Clinico-pathological conference. J. Mt Sinai Hosp., 26, 324.

Siebert, F. T., and Fisher, E. R. (1957). Bronchiolar emphysema, so-called muscular cirrhosis of the lungs. Amer. J. Path., 33, 1137.

Turner-Warwick, M., and Doniach, D. (1965). Auto-antibody studies in interstitial pulmonary fibrosis. Brit. med. J., 1, 886. 